\title{
Large-scale molecular dynamics simulations of TiN/TiN(001) epitaxial film growth
}

\author{
Daniel Edström, Davide Sangiovanni, Lars Hultman, Ivan Petrov, Joseph E Greene and \\ Valeriu Chirita \\ Journal Article
}

\section{Tweet}

N.B.: When citing this work, cite the original article.

Original Publication:

Daniel Edström, Davide Sangiovanni, Lars Hultman, Ivan Petrov, Joseph E Greene and Valeriu Chirita, Large-scale molecular dynamics simulations of TiN/TiN(001) epitaxial film growth, Journal of Vacuum Science \&amp; Technology. A. Vacuum, Surfaces, and Films, 2016. 34(4), pp.041509-1-041509-9.

http://dx.doi.org/10.1116/1.4953404

Copyright: AIP Publishing

http://www.aip.org/

Postprint available at: Linköping University Electronic Press

http://urn.kb.se/resolve?urn=urn:nbn:se:liu:diva-130405

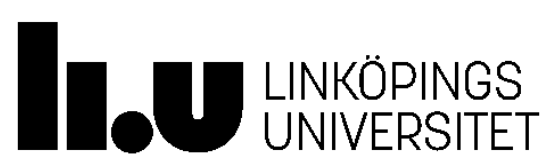




\section{Large-scale molecular dynamics simulations of TiN/TiN(001) epitaxial film growth}

Running title: Large-scale MD simulations of TiN/TiN(001) epitaxial film growth

Running Authors: Edström et al.

\section{Daniel Edströma)}

Linköping University, Department of Physics, Chemistry, and Biology (IFM), SE-58183 Linköping, Sweden

\section{Davide Giuseppe Sangiovanni}

Linköping University, Department of Physics, Chemistry, and Biology (IFM), SE-58183 Linköping, Sweden

\section{Lars Hultman}

Linköping University, Department of Physics, Chemistry, and Biology (IFM), SE-58183 Linköping, Sweden

\section{Ivan Petrov}

University of Illinois at Urbana-Champaign, Frederick Seitz Materials Research Laboratory and the Materials Science Department, Urbana, Illinois 61801, USA

Linköping University, Department of Physics, Chemistry, and Biology (IFM), SE-58183 Linköping, Sweden

\section{J. E. Greene}

University of Illinois at Urbana-Champaign, Frederick Seitz Materials Research Laboratory and the Materials Science Department, Urbana, Illinois 61801, USA

Linköping University, Department of Physics, Chemistry, and Biology (IFM), SE-58183 Linköping, Sweden

\section{Valeriu Chirita}

Linköping University, Department of Physics, Chemistry, and Biology (IFM), SE-58183 Linköping, Sweden

a) Electronic mail: daned@ifm.liu.se

Large-scale classical molecular dynamics (CMD) simulations of epitaxial TiN/TiN(001) thin film growth at $1200 \mathrm{~K}$ are carried out using incident flux ratios $\mathrm{N} / \mathrm{Ti}=1,2$, and 4 . 
The films are analyzed as a function of composition, island size distribution, island edge orientation, and vacancy formation. Results show that $\mathrm{N} / \mathrm{Ti}=1$ films are globally understoichiometric with dispersed Ti-rich surface regions which serve as traps to nucleate 111-oriented islands, leading to local epitaxial breakdown. Films grown with $\mathrm{N} / \mathrm{Ti}=2$ are approximately stoichiometric and the growth mode is closer to layer-bylayer, while $\mathrm{N} / \mathrm{Ti}=4$ films are stoichiometric with $\mathrm{N}$-rich surfaces. As N/Ti is increased from 1 to 4, island edges are increasingly polar, i.e. 110-oriented, and N-terminated to accommodate the excess $\mathrm{N}$ flux, some of which is lost by reflection of incident $\mathrm{N}$ atoms. $\mathrm{N}$ vacancies are produced in the surface layer during film deposition with $\mathrm{N} / \mathrm{Ti}=1$ due to the formation and subsequent desorption of $\mathrm{N} 2$ molecules composed of a $\mathrm{N}$ adatom and a $\mathrm{N}$ surface atom, as well as itinerant Ti adatoms pulling up $\mathrm{N}$ surface atoms. The $\mathrm{N}$ vacancy concentration is significantly reduced as $\mathrm{N} / \mathrm{Ti}$ is increased to 2 ; with $\mathrm{N} / \mathrm{Ti}=4, \mathrm{Ti}$ vacancies dominate. Overall, our results show that an insufficient N/Ti ratio leads to surface roughening via nucleation of small dispersed 111 islands, whereas high N/Ti ratios result in surface roughening due to more rapid upper-layer nucleation and mound formation. The growth mode of $\mathrm{N} / \mathrm{Ti}=2$ films, which have smoother surfaces, is closer to layer-by-layer.

\section{INTRODUCTION}

Transition-metal (TM) nitride coatings ${ }^{1-3}$ are presently employed in a wide variety of applications due to their unique combination of properties including high hardness, ${ }^{1,45}$ excellent scratch and abrasion resistance, ${ }^{6}$ low coefficient of friction, ${ }^{7}$ high- 
temperature oxidation resistance, ${ }^{8-10}$ electrical conductivity ranging from metallic to semiconducting, ${ }^{11-14}$ optical adsorption which can be tuned across the visible spectrum, ${ }^{15}$ and superconductivity. ${ }^{11,16,17} \mathrm{TiN}_{\mathrm{x}}$, which has a wide single-phase field ranging from $\mathrm{x}=$ 0.6 to $1.0,,^{18,19}$ is one of the first hard-coating materials and serves as a model system for NaCl-structure TM nitride compounds and alloys. Thus, TiN has been extensively investigated experimentally to probe nucleation, ${ }^{20,21}$ growth, ${ }^{22-25}$ and microstructure evolution. ${ }^{26,27}$

The development of a fundamental understanding of processes governing nanostructural and surface morphological evolution during thin-film growth requires detailed information about the dynamics of adatom transport on surfaces, island nucleation, and the early stages of growth. State-of-the-art atomic-scale experimental techniques, such as scanning tunneling microscopy $y^{22,23,28}$ and low-energy electron microscopy, ${ }^{29,30}$ are unable to resolve picosecond surface dynamics, necessitating the use of complementary computational investigations. System sizes required for film-growth studies are prohibitively large for ab-initio methods such as density functional theory (DFT). This renders classical molecular dynamics (CMD) as the primary computational method to study large-scale film growth dynamics.

In previous CMD studies, dedicated to mass transport on $\operatorname{TiN}(001)$ terraces $^{31}$ and TiN/TiN(001) $)^{32,33}$ islands, we demonstrated that surface mobilities of $\mathrm{Ti}$ and $\mathrm{N}$ adatoms, as well as $\mathrm{TiN}_{\mathrm{x}}$ admolecules, vary significantly with the incident nitrogen/metal flux ratio. On infinite $\mathrm{TiN}(001)$ terraces at $1000 \mathrm{~K}, \mathrm{Ti}$ adatom migration velocities are nearly three times that of $\mathrm{N}$ adatoms. For $\operatorname{TiN}_{\mathrm{x}}$, the translation probability decreases, while the probability for admolecule rotation increases, as $\mathrm{x}$ is increased from 1 to 3 . The high 
rotation rates result in surprisingly high mobilities for $\mathrm{TiN}_{2}$ admolecules, nearly half that of $\mathrm{Ti}$ adatoms, while $\mathrm{TiN}_{3}$ admolecules simply rotate around their centers of mass yielding no net diffusion. ${ }^{31}$ On small $\mathrm{TiN} / \mathrm{TiN}(001)$ islands, both $\mathrm{TiN}$ and $\mathrm{TiN}_{2}$ admolecules are more efficient carriers of $\mathrm{Ti}$ atoms than $\mathrm{Ti}$ adatoms themselves. For interlayer mass transport over step edges, $\mathrm{TiN}_{2}$ admolecules are the most efficient carriers of both $\mathrm{Ti}$ and $\mathrm{N}$ atoms. In contrast, $\mathrm{TiN}_{3}$ admolecules are essentially stationary on TiN/TiN(001) islands as well as on TiN(001) terraces. ${ }^{33}$ Thus, the net N/Ti adsorption ratio during film growth, which determines the relative surface concentrations of adatoms and $\mathrm{TiN}_{\mathrm{x}}$ admolecules, is a key parameter for understanding $\mathrm{TiN}_{\mathrm{x}}$ growth dynamics.

Here, we use large-scale classical molecular dynamics (CMD) simulations of TiN/TiN(001) epitaxy at $1200 \mathrm{~K}$, carried out using incident flux ratios N/Ti = 1, 2, and 4, to probe stoichiometry, island-size distribution, island-edge orientation, and vacancy formation during early stages of film growth. Overall, our results show that increasing the N/Ti flux ratio yields flatter films whose growth mode, with $\mathrm{N} / \mathrm{Ti}=2$, is closer to layerby-layer and island edge orientations change from mixed 100 and 110 to predominantly N-terminated $110(\mathrm{~N} / \mathrm{Ti}=4)$. Substrate surface vacancy formation shifts from being dominated by $\mathrm{N}$-vacancies with $\mathrm{N} / \mathrm{Ti}=1$ to Ti-vacancies with $\mathrm{N} / \mathrm{Ti}=4$. For film growth with $\mathrm{N} / \mathrm{Ti}=1$, we observe local Ti-deficient surface regions which result in the formation of 111-oriented islands leading to local epitaxial breakdown and a rougher surface morphology.

\section{MODELLING}

We perform large-scale CMD simulations of TiN/TiN(001) film growth at 1200 K, within the optimal range of $\mathrm{TiN}(001)$ epitaxial growth, ${ }^{13,34}$ with three incident $\mathrm{N} / \mathrm{Ti}$ 
flux ratios: 1,2 , and 4 . The simulations are carried out using the modified embedded atom method (MEAM) ${ }^{35}$ interatomic potential as implemented in the Large-scale Atomic/Molecular Massively Parallel Simulator (LAMMPS) ${ }^{36}$ with the TiN parameterization employed in references. ${ }^{31-33,37,38}$ The predictions of the parameterization were previously validated using DFT-based ab-initio molecular dynamics calculations to determine $\mathrm{Ti}^{37}$ and $\mathrm{N}^{38}$ diffusion kinetics on, as well as $\mathrm{N}_{2}$ desorption kinetics from, ${ }^{38}$ TiN(001) surfaces.

The timestep in the present simulation experiments is $1 \mathrm{fs}$ and the substrate size is 100x100x6 atoms of NaCl-structure $\operatorname{TiN}(001)$, for a total of 60000 atoms. The nearestneighbor interatomic distance is $2.121 \AA$, equivalent to a lattice constant of $4.242 \AA$. Periodic boundary conditions are applied along in-plane directions only. During deposition, atoms in the bottom layer are fixed, while atoms in the second and third lowest layers are subject to velocity rescaling at each time-step in order to maintain a constant temperature of $1200 \mathrm{~K}$. The top three layers are free of constraints. Every 25000 timesteps, or 25 ps, we alternately add either a Ti atom or 1 to $4 \mathrm{~N}$ atoms, depending on the chosen flux ratio. All $\mathrm{N}$ atoms are added simultaneously. The atoms are randomly inserted at positions ranging 10.5 to $12.5 \AA$ above the substrate surface. The incident atoms are assigned a random velocity, within a $30^{\circ}$ angle from normal incidence, corresponding to an average energy of $2 \mathrm{eV}$. This is achieved by independently assigning random velocity components in the intervals of $-\mathrm{a} \leq \mathrm{v}_{\mathrm{x}} \leq \mathrm{a},-\mathrm{a} \leq \mathrm{v}_{\mathrm{y}} \leq \mathrm{a}$, and $-2 \sqrt{6} \mathrm{a} \leq \mathrm{v}_{\mathrm{z}}$ $\leq-\sqrt{6}$ a. The value of a is chosen such that the kinetic energy expectation value for $\mathrm{Ti}$ and $\mathrm{N}$ atoms is $2 \mathrm{eV}$. An energy of $2 \mathrm{eV}$ corresponds approximately to thermal atoms accelerated by the substrate surface potential. ${ }^{39}$ The positions of upper-layer substrate 
atoms and the deposited atoms are stored every 1000 timesteps (1 ps) in MD videos which are visualized using Visual Molecular Dynamics. ${ }^{40}$ We simulate $\tau=212.5$ ns of deposition time in which $4250 \mathrm{Ti}$ atoms are incident at the substrate and growing film. For ideal stoichiometric layer-by-layer growth, this corresponds to a surface coverage of 0.85 monolayers (ML). A coverage of $0.85 \mathrm{ML}$ in $212.5 \mathrm{~ns}$ corresponds to a growth rate of $1.41 \times 10^{5} \AA \mathrm{min}^{-1}$, a factor of only $10^{2}-10^{3}$ higher than typical experiment results with epitaxial DC magnetron sputtering. ${ }^{5}$ In total, the simulations required, for each flux ratio, approximately 1000 hours of computation using 32 8-core, 2.2 GHz, Intel Xeon E5-2660 Sandy Bridge processors. During the simulations, atoms are free to leave the simulation box. As the net Ti capture probability is essentially unity, this is primarily an issue for $\mathrm{N}$ atoms, which can leave either by direct reflection or through $\mathrm{N}_{2}$ desorption as a $\mathrm{N}$ adatom bonds with, and removes, a $\mathrm{N}$ surface atom..$^{38,41}$

\section{RESULTS AND DISCUSSION}

Figures 1(a)-1(c) show the positions of all deposited atoms at the end of deposition sequences ( $\tau=212.5 \mathrm{~ns}$ ) corresponding to total Ti coverages $\theta_{\mathrm{Ti}}$ of $0.81,0.84$, and 0.82 ML for the three flux ratios, $\mathrm{N} / \mathrm{Ti}=1,2$, and 4 . The total number of condensed Ti and $\mathrm{N}$ atoms are also plotted as a function of Ti first-layer coverage $\theta_{\mathrm{Ti}, 1}$ for each film. The $\operatorname{TiN}_{\mathrm{x}}$ film grown using a N/Ti flux ratio of one is globally understoichiometric with $\mathrm{x}=0.65$, while the film grown with $\mathrm{N} / \mathrm{Ti}=2$ is slightly overstoichiometric, $\mathrm{x}=1.10$, and the $\mathrm{N} / \mathrm{Ti}=4$ film is globally overstoichiometric with $\mathrm{x}=1.49$. Locally, however, the islands of $\mathrm{N} / \mathrm{Ti}=2$ and 4 films are nearly stoichiometric, as shown below, with the excess $\mathrm{N}$ terminating polar edges of 110 -oriented islands. During the initial stages of film growth, corresponding to deposition of $\leq 500 \mathrm{~N}$ atoms, net $\mathrm{N}$ capture probabilities are 
approximately equal for the three flux ratios, $\mathrm{N} / \mathrm{Ti}=1,2$, and 4 , at $0.55,0.53$, and 0.55 , respectively, as $\mathrm{N}$ adatoms behave as a two-dimensional gas and interact primarily with clean TiN(001) surfaces. With further deposition, $\mathrm{N}$ capture probabilities change due to corresponding time- and surface-concentration-dependent changes in $\mathrm{N}_{2}$ desorption rates. For the final 500 deposited $\mathrm{N}$ atoms, the net capture probabilities are $0.70,0.49$, and 0.30 , respectively. The $\mathrm{N}$ capture probability is related to the slope of the $\mathrm{n}_{\mathrm{N}}$ curves in Fig. 1 via the N/Ti ratio. 


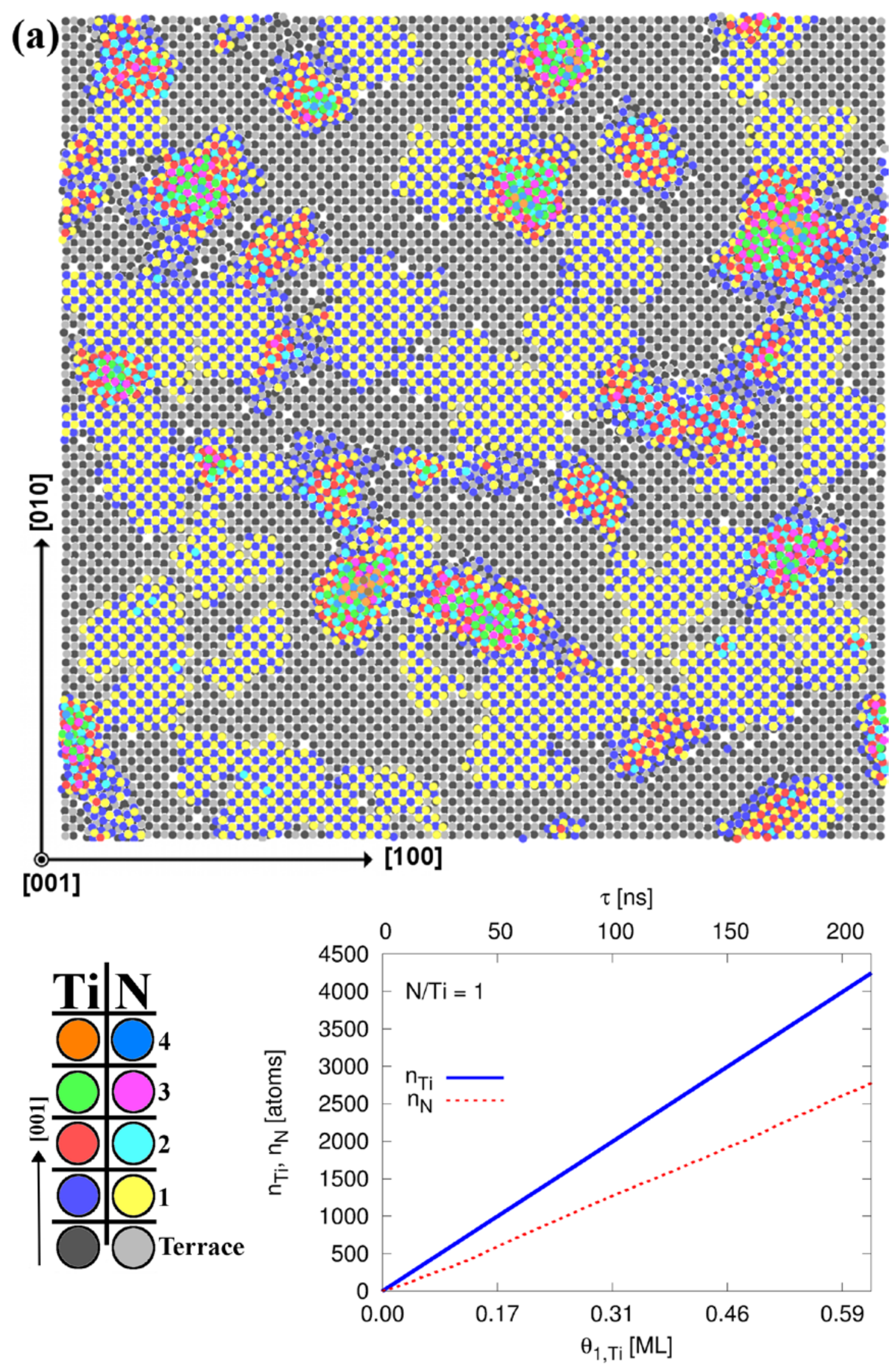




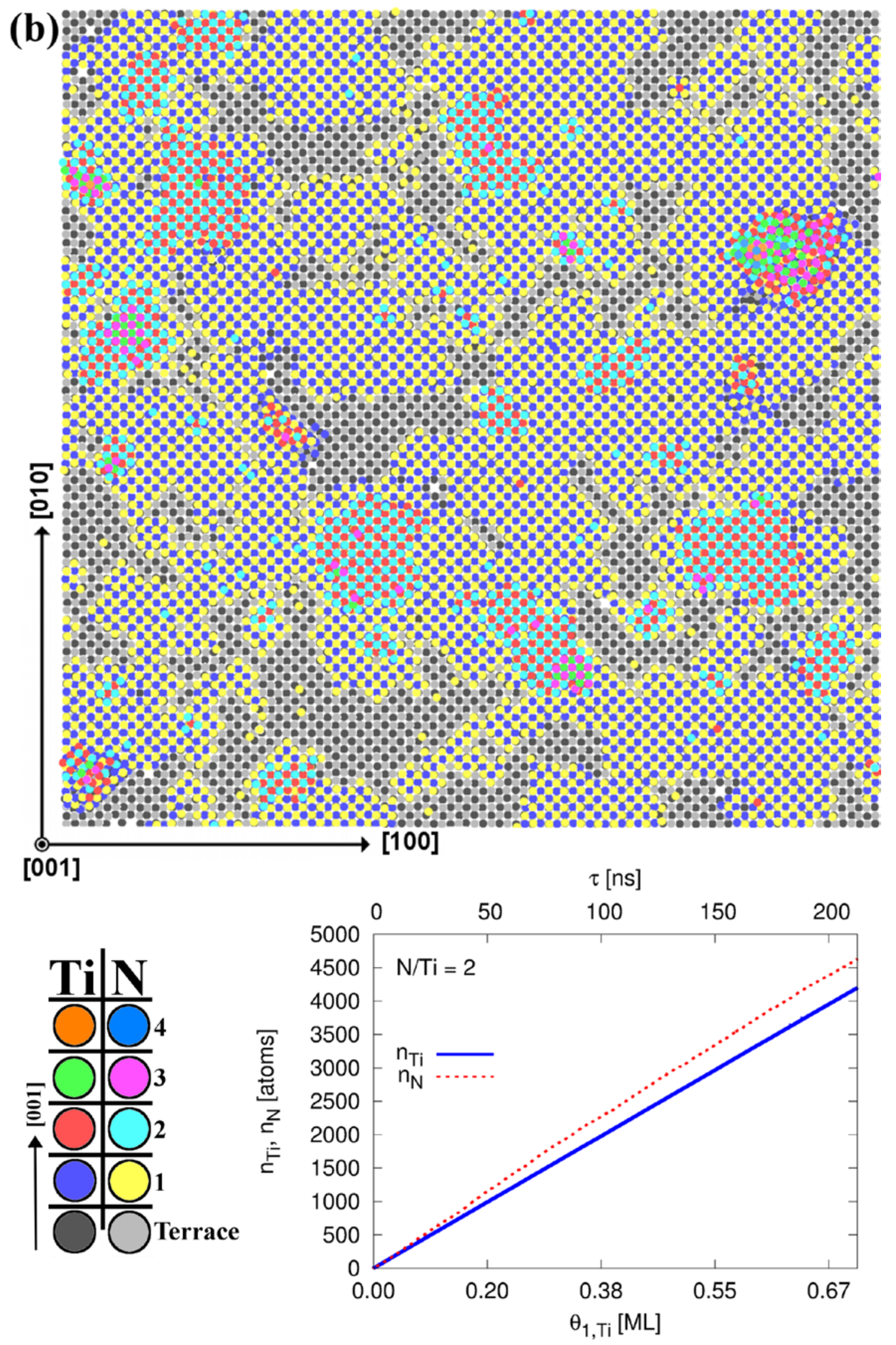



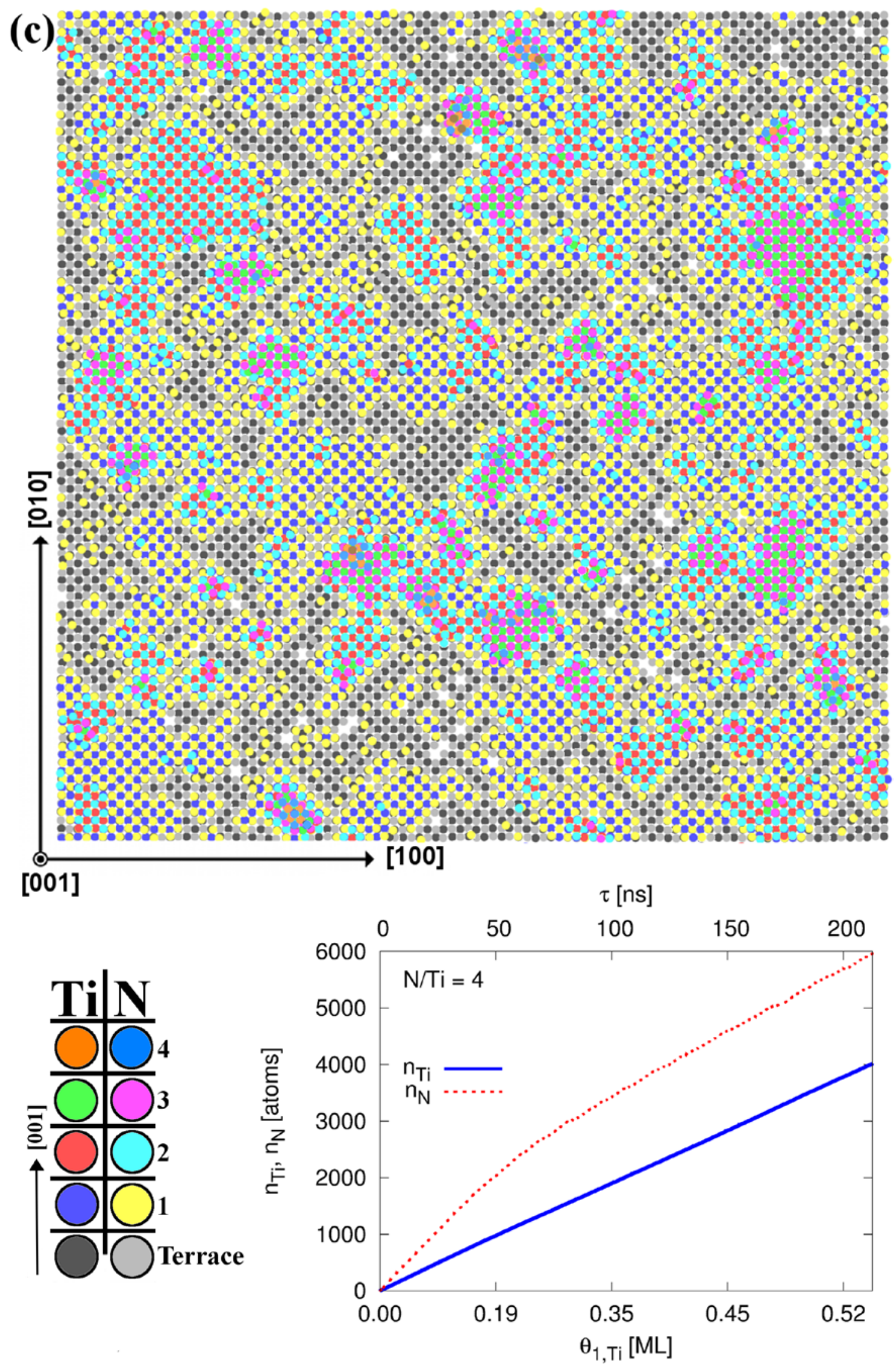
FIG. 1. Positions, viewed along 001, of all deposited atoms (upper panels) during TiN/TiN(001) film growth at $1200 \mathrm{~K}$ following total incident Ti exposures of 4250 atoms with N/Ti ratios of (a) one, (b) two, and (c) four. The substrate size is $2121 \times 2121 \AA^{2}$ (100x100 atoms). Ti and $\mathrm{N}$ atoms are color coded by layer number as shown in the legend. The layer numbers are defined by intervals of $2.1 \AA$ in the growth direction. The lower panels in (a), (b), and (c) are plots of the total numbers of captured Ti and $\mathrm{N}$ atoms $\left(\mathrm{n}_{\mathrm{Ti}}\right.$ and $\mathrm{n}_{\mathrm{N}}$ ) as a function of Ti coverage in the first layer $\theta_{1, \mathrm{Ti}}[\mathrm{ML}] . \tau$ is the deposition time.

The TiN/TiN(001) island structures in the three cases are strikingly different. For $\mathrm{N} / \mathrm{Ti}=1$ [FIG. 1(a)], film growth occurs in the 2D multilayer mode, local layer-by-layer growth with global surface roughening via mound formation, leading to many secondlayer islands (32 of them) as well as third- (14) and fourth-layer (4) islands. This is attributed to limited interlayer transport; the low N/Ti flux ratio results in relatively few TiN and $\mathrm{TiN}_{2}$ admolecules, the species which rapidly descend over step edges. ${ }^{33}$ The overall film composition is $\mathrm{TiN}_{0.65}$ and the total fractional coverages of the first four layers are $\theta_{1}^{\mathrm{t}}=0.55 \mathrm{ML}, \theta_{2}^{\mathrm{t}}=0.11 \mathrm{ML}, \theta_{3}^{\mathrm{t}}=0.03 \mathrm{ML}$, and $\theta_{4}^{\mathrm{t}}=0.01 \mathrm{ML}$. We observe, in each layer of N/Ti $=1$ films, the formation of local Ti-rich (111)-oriented surface regions, in which the atoms are located in non-epitaxial positions; the first-layer 111 coverage $\theta_{1}^{\mathrm{t}, 111}$ is approximately $0.18 \mathrm{ML}$.

The relatively low layer coverages characterizing $\mathrm{N} / \mathrm{Ti}=1$ growth are primarily due to nitrogen deficiency resulting from $\mathrm{N}$ reflection and $\mathrm{N}_{2}$ desorption. This leads, in turn, to the formation of three-dimensional (3D) islands as underdense, non-epitaxial Tirich regions act as traps for incoming atoms. In addition, $61 \mathrm{~N}$ vacancies and $3 \mathrm{Ti}$ vacancies are formed in the top layer of the substrate due to migrating adatoms (in this case, $\mathrm{Ti}$ is the dominant adatom species) pulling atoms of the opposite type out of the surface layer. The first layer of the deposited film contains $7 \mathrm{~N}$ vacancies and $3 \mathrm{Ti}$ 
vacancies. We also observe $\mathrm{N}$ surface vacancies resulting from the formation and rapid desorption of strongly-bonded $\mathrm{N}_{\text {ad }} / \mathrm{N}_{\text {surf }}$ pairs $\left(\mathrm{N}_{\text {ad }}\right.$ is a $\mathrm{N}$ adatom and $\mathrm{N}_{\text {surf }}$ is a surface $\mathrm{N}$ atom) as previously reported. ${ }^{38}$

TiN islands grown with N/Ti $=1$ are bounded by both [100]- and [110]-oriented edges with approximately equal total edge lengths, $\mathrm{L}_{100} \simeq \mathrm{L}_{110}$; there is a total of 389.5 epitaxial atoms along [100] edges and 341.5 epitaxial atoms along [110] edges (the fractional atoms arise due to shared 100/110 corners). The number density of islands with four or more atoms is $1.56 \times 10^{-4} \AA^{-2}$. The choice of four atoms as a lower-limit for island size is motivated by the role of the $\mathrm{TiN}_{3}$ admolecule as the smallest stationary nucleation cluster. ${ }^{31}$ The largest island consists of nearly 4000 atoms, and there are five islands with sizes between 50 and 1000 atoms.

Films grown with a N/Ti flux ratio of two, FIG. 1(b), are much flatter with fewer second- and higher-layer islands. The first-, second-, and third-layer total coverages are $\theta_{1}^{\mathrm{t}}=0.73 \mathrm{ML}, \theta_{2}^{\mathrm{t}}=0.14 \mathrm{ML}$, and $\theta_{3}^{\mathrm{t}}=0.01 \mathrm{ML} .13 \mathrm{~N}$ vacancies and $8 \mathrm{Ti}$ vacancies are formed in the substrate surface layer, and $7 \mathrm{~N}$ vacancies and $9 \mathrm{Ti}$ vacancies in the first layer of the deposited film. Islands in N/Ti = 2 films are primarily bounded by 110 edges: 287 atoms along 100 edges vs. 554 atoms along 110 edges. The island number density is $6.67 \times 10^{-5} \AA^{-2}$ and the first layer is dominated by one large island of more than 7000 atoms. The formation of 111-oriented regions is strongly suppressed, with $\theta_{1}^{\mathrm{t}, 111}=0.02$ ML.

Films grown with a N/Ti flux ratio of four, FIG. 1(c), have total layer coverages $\theta_{1}^{\mathrm{t}}=0.65, \theta_{2}^{\mathrm{t}}=0.27, \theta_{3}^{\mathrm{t}}=0.08$, and $\theta_{4}^{\mathrm{t}}=0.01 \mathrm{ML}$. Surface morphologies are rougher than those of films grown with $\mathrm{N} / \mathrm{Ti}=2$ and vacancy concentrations are 
dominated by Ti rather than N. $62 \mathrm{Ti}$ vacancies and $1 \mathrm{~N}$ vacancy are formed in the substrate surface layer, while the first deposited layer contains $25 \mathrm{Ti}$ vacancies and $1 \mathrm{~N}$ vacancy. The predominance of 110- over 100-oriented edges is even more pronounced; there are 116 atoms along 100 edges and 926 atoms along 110 edges with an island number density of $5.78 \times 10^{-4} \AA^{-2}$. The film consists of one large first-layer island of almost 6000 atoms together with 25 islands having fewer than 100 atoms. All islands are epitaxial and the formation of 111-oriented regions is completely suppressed, $\theta_{1}^{\mathrm{t}, 111}=$ $0.00 \mathrm{ML}$.

Figures. 2(a)-2(c), showing first-layer island structures (i.e., the upper layers have been removed) after total incident Ti exposures of 4250 atoms $(\tau=212.5 \mathrm{~ns})$ with $\mathrm{N} / \mathrm{Ti}$ ratios of 1, 2, and 4, provide additional insight into the morphological evolution of island growth. With N/Ti = 1, FIG. 2(a), there are several 111-oriented non-epitaxial metal-rich islands, consisting primarily of Ti adatoms in fourfold-hollow sites. The 111 islands form due to severe local nitrogen deficiency. The overall composition of the first layer is $\mathrm{TiN}_{0.78}$, while non-epitaxial first-layer regions have an average composition of $\mathrm{TiN}_{0.46}$. First-layer elemental coverages are $\theta_{1, \mathrm{Ti}}=0.61$ and $\theta_{1, \mathrm{~N}}=0.48 \mathrm{ML}$ (total film elemental coverages are $\theta_{\mathrm{tot}, \mathrm{Ti}}=0.81$ and $\theta_{\mathrm{tot}, \mathrm{N}}=0.60 \mathrm{ML}$ ). Upon increasing the $\mathrm{N} / \mathrm{Ti}$ ratio to 2, FIG. 2(b), the formation of metal-rich regions is suppressed; only one such area is observed. The first-layer elemental coverages increase to $\theta_{1, \mathrm{Ti}}=0.69$ and $\theta_{1, \mathrm{~N}}=0.77$ ML (total film elemental coverages are $\theta_{\mathrm{tot}, \mathrm{Ti}}=0.84$ and $\theta_{\mathrm{tot}, \mathrm{N}}=0.93 \mathrm{ML}$ ). With $\mathrm{N} / \mathrm{Ti}=4$, FIG. 2(c), all islands are epitaxial and the first-layer Ti coverage is reduced to $\theta_{1, \mathrm{Ti}}=0.54$ ML due to $\mathrm{N}$ adatoms pulling underlying Ti atoms to higher layers. The first-layer $\mathrm{N}$ coverage remains the same as for $\mathrm{N} / \mathrm{Ti}=2$ films, $\theta_{1, \mathrm{~N}}=0.77 \mathrm{ML}$ (total elemental 
coverages are $\theta_{\text {tot,Ti }}=0.82 \mathrm{ML}$ and $\theta_{\text {tot, } \mathrm{N}}=1.19 \mathrm{ML}$ ). However, as noted below, the

excess $\mathrm{N}$ is due to $\mathrm{N}$-terminated polar 110 island edges.

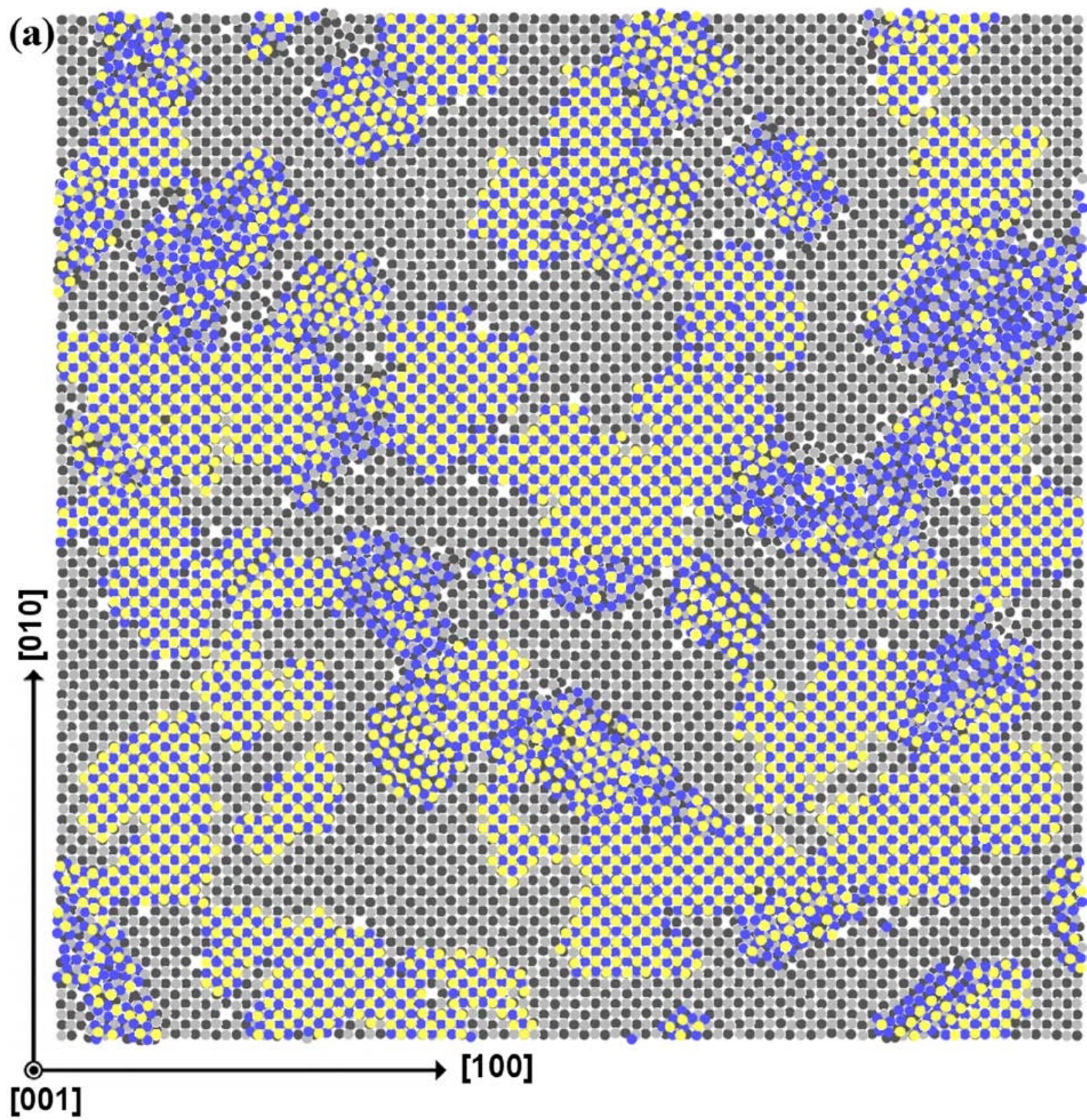




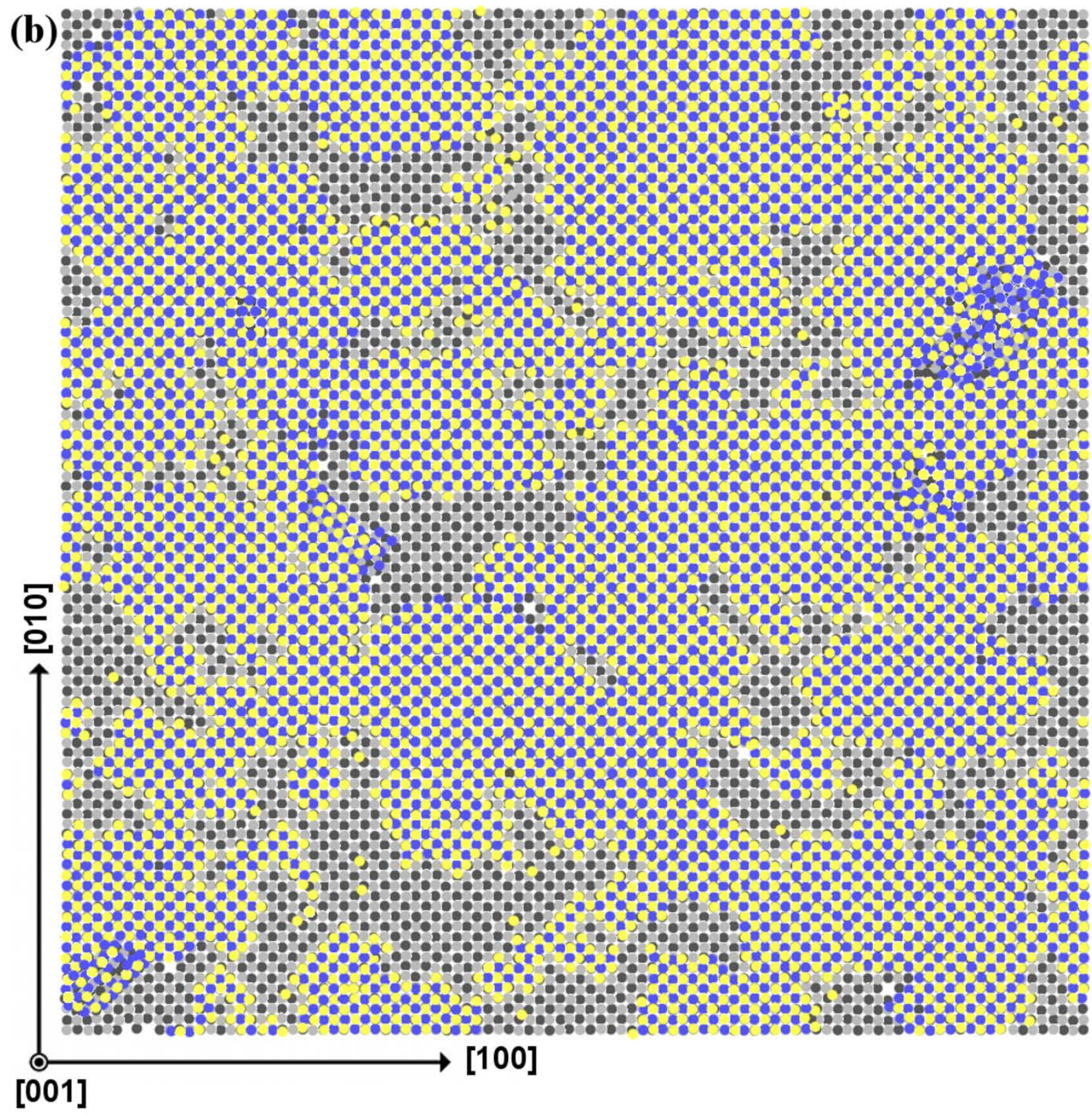




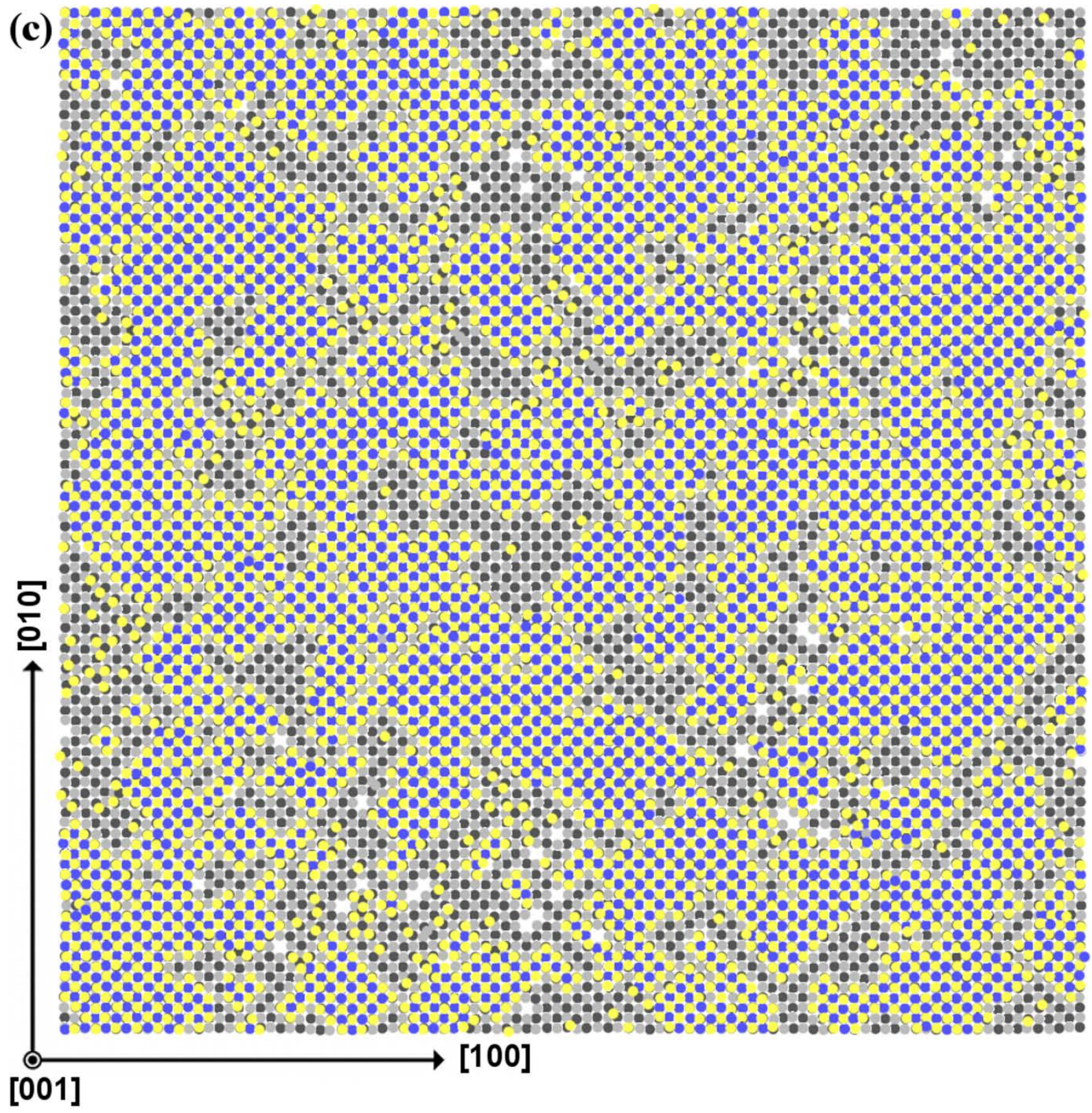

FIG. 2. Positions, viewed along 001, of all deposited atoms in the first layer during TiN/TiN(001) film growth at $1200 \mathrm{~K}$ following total incident Ti exposures of 4250 atoms with N/Ti ratios of (a) one, (b) two, and (c) four. The substrate size is $2121 \times 2121 \AA^{2}$ (100x100 atoms). Ti and $\mathrm{N}$ atoms are color coded as shown in Figure 1.

In order to understand the nucleation of 111-oriented surface regions due to local $\mathrm{N}$ deficiency, we rerun $5 \mathrm{~ns}$ of the simulation, starting at $\tau=12.5 \mathrm{~ns}$, to produce highresolution video files. The position of upper-layer substrate atoms and deposited atoms 
are stored every 25 fs instead of every 1000 fs. Based upon a detailed analysis of the videos, we identify three key structures, illustrated in Figure 3, which are common motifs for film growth under $\mathrm{N}$ deficient conditions.

Square $\mathrm{Ti}_{2} \mathrm{~N}_{2}$ islands, with 100 edges, illustrated in FIG. 3(a), serve as seeds for the growth of the 001-oriented epitaxial islands in FIG. 2(a). The triangular admolecules, shown in Figure 3(b), consist of three Ti adatoms residing in fourfold-hollow sites with one $\mathrm{N}$ adatom in the central epitaxial atop position. The capture of an incident Ti atom or an itinerant Ti adatom leads to island reshaping and the formation of a pentamer [FIG. 3(c)] structure with four $\mathrm{Ti}$ and one $\mathrm{N}$, all occupying adjacent fourfold-hollow sites. Under N-deficient deposition conditions, pentamers grow into ladder-like structures along 110 directions [FIG. 3(d)]. The ladder structures are very stable and serve as initiators for the formation of 111-oriented islands. When a 110 ladder structure grows laterally (i.e., along 110 directions as illustrated in FIG. 3(d)), the additional atoms do not occupy fourfold-hollow sites. $\mathrm{N}$ atoms bonded directly to Ti ladder atoms, which occupy fourfold-hollow positions, are situated 2.8-3.0 $\AA$ above N substrate atoms. The next set of atoms in the 110 direction (away from the central ladder structure) are Ti and $\mathrm{N}$ atoms in threefold-hollow sites on each side of substrate Ti atoms. The following row consists of Ti atoms in epitaxial positions with $\mathrm{N}$ atoms in fourfold-hollow sites. As highlighted in FIG. 3(e), this results in a 111-oriented island with a hexagonal surface unit cell. We also observe similar 111 structures which are shifted by one nearest-neighbor distance in the 100 direction. We note that $\mathrm{N}$ deficiency is only necessary to nucleate local 111-oriented surface regions while subsequent film growth may result in stoichiometric 111 islands as illustrated in Figure 3(e). 
(a)

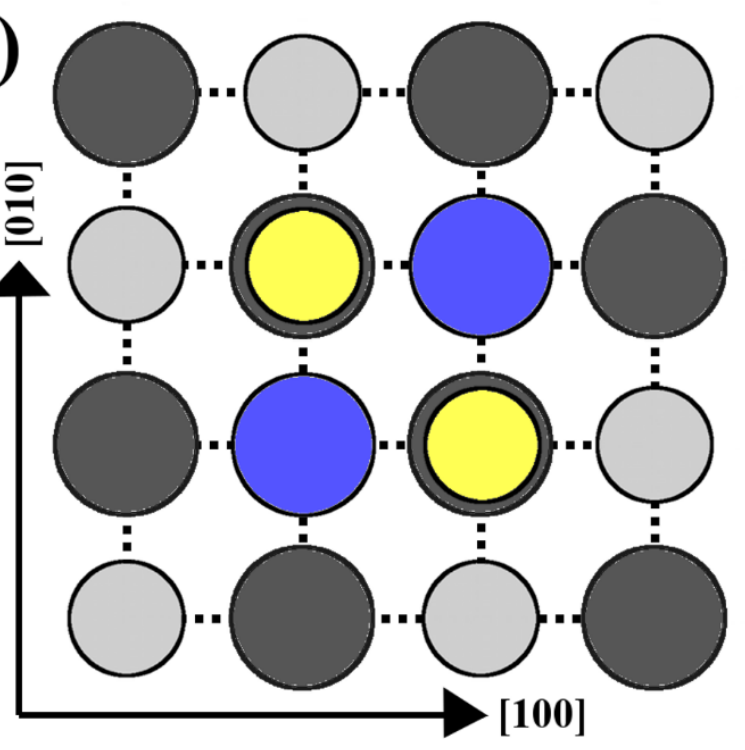

(b)

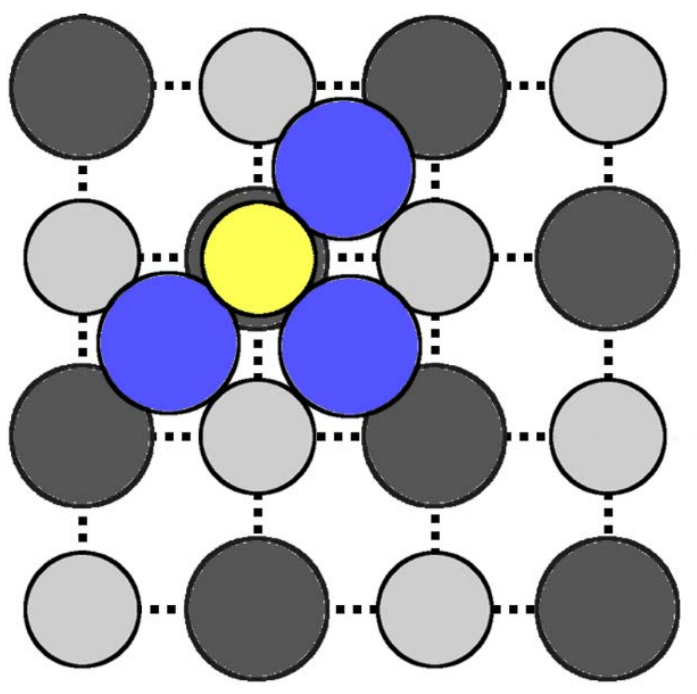


(c)

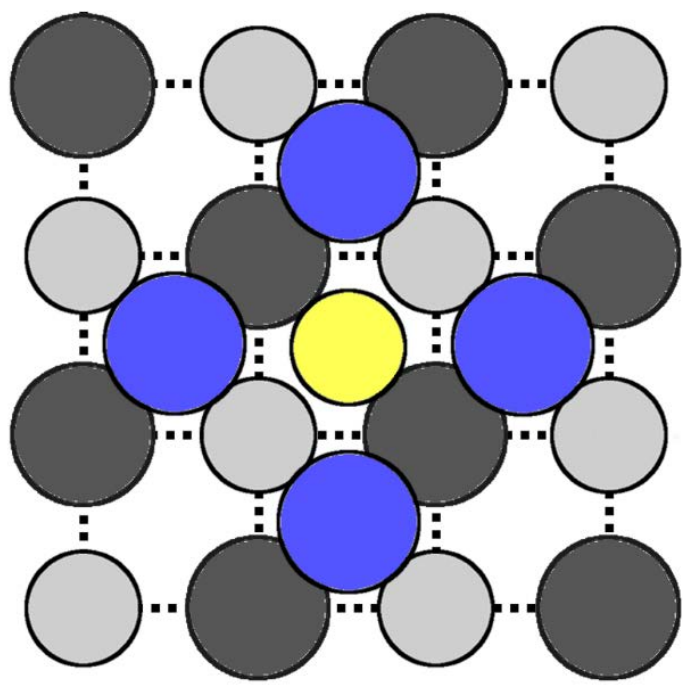

(d)

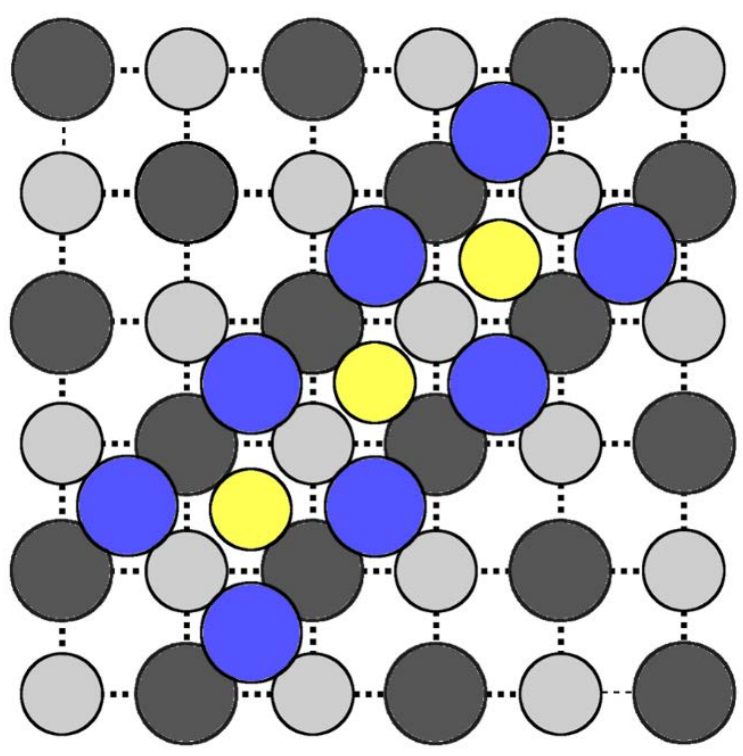




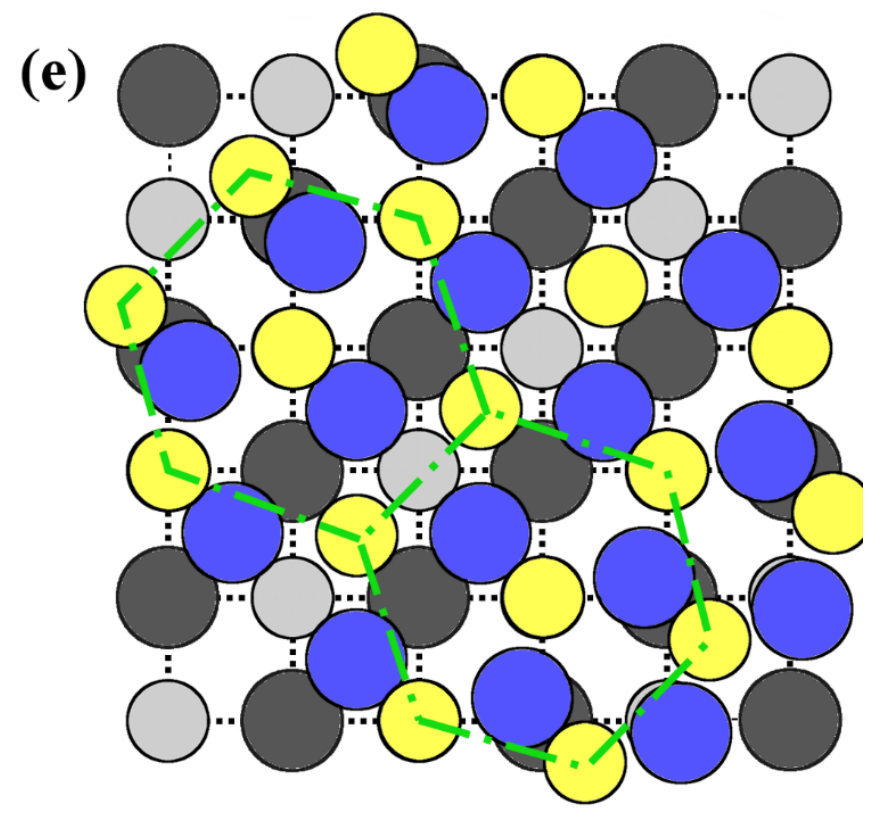

FIG. 3. Common island structures during TiN/TiN(001) film growth at $1200 \mathrm{~K}$ with N/Ti $=1$. All panels are oriented $<100>$ in the horizontal direction and $<010>$ vertically. (a) $\mathrm{Ti}_{2} \mathrm{~N}_{2}$ square island with 100 edges and all atoms in epitaxial atop positions. (b) Triangular island with three Ti atoms in fourfold-hollow sites and a $\mathrm{N}$ atom in an epitaxial atop position. (c) $\mathrm{Ti}_{4} \mathrm{~N}$ pentamer structure with all atoms in fourfold-hollow sites. (d) Ladder-like structure consisting of pentamer chains in which both Ti and N atoms are in fourfoldhollow sites. (e) A 111-oriented TiN/TiN(001) island formed from a ladder structure island by growth in $1 \overline{10}$ directions. The hexagonal unit cell is highlighted with green dash/dot lines.

Figure 4 consists of island-size histograms determined after 212.5 ns of deposition $\left(\theta_{\text {tot,Ti }}=0.81,0.84\right.$, and $0.82 \mathrm{ML}$ with $\mathrm{N} / \mathrm{Ti}=1,2$, and 4$)$. The horizontal axes correspond to island sizes, expressed as a range in the number of atoms per island, and the vertical axes specify the total number of atoms residing in islands of the corresponding size. Islands in the first, second, third, and fourth layers are indicated by blue diagonal stripes, red horizontal stripes, green zig-zag, and purple checkered bars, respectively. The total island number densities are $1.56 \times 10^{-4}, 6.67 \times 10^{-5}$, and $5.78 \times 10^{-4} \AA^{-2}$ for $\mathrm{N} / \mathrm{Ti}=1,2$, and 4. 

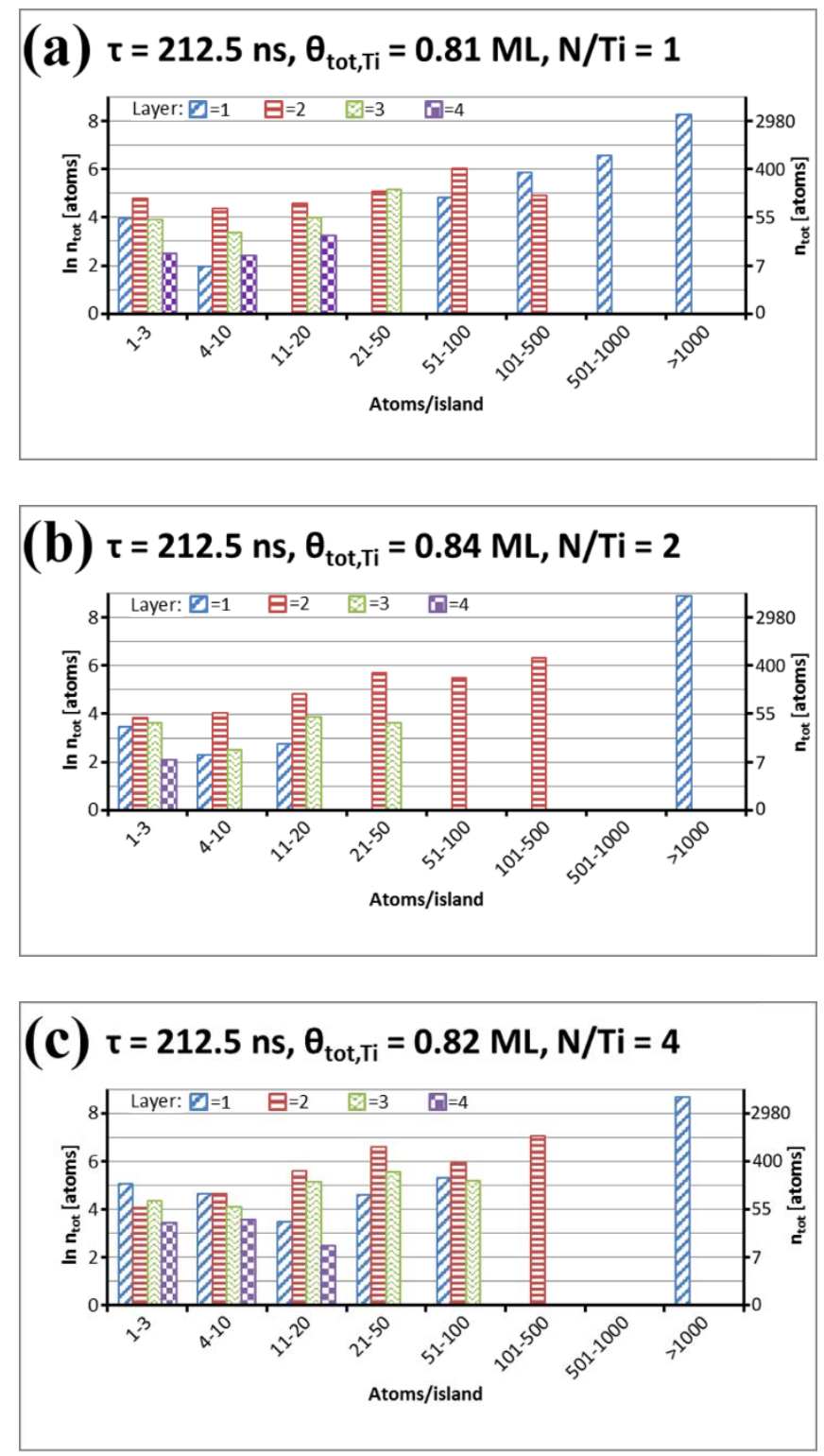

FIG. 4. TiN/TiN(001) island size distributions as a function of layer number following total incident $\mathrm{Ti}$ exposures of 4250 atoms with N/Ti ratios of (a) one, (b) two, and (c) four during film growth at $1200 \mathrm{~K}$. The substrate size is $2121 \times 2121 \AA^{2}$ (100x100 atoms). Island size distributions are plotted as the logarithm of the total number of atoms $n_{\text {tot }}$ vs. island size in units of the total number of atoms per island.

With $\mathrm{N} / \mathrm{Ti}=1$ [FIG. 4(a)], there is a large first-layer island of 3904 atoms, as well as five islands in the 51-1000 atom range. In the second layer, the largest island is 133 atoms. There are five islands of size 21-50 atoms in the third layer, and two islands with 
11-20 atoms in the fourth layer. For films grown with N/Ti $=2$ [FIG. 4(b)], the first layer is dominated by a very large island of 7230 atoms; there are no other first-layer islands with sizes above 16 atoms. In the second layer, there are four islands in the 101-500 atom size range residing on the large first-layer island and there is one island with 37 atoms in the third layer together with five islands with between 4 and 20 atoms. With N/Ti $=4$, the largest first-layer island contains 5914 atoms. Compared to the two lower N/Ti films, there is a larger number, 25, of islands with $<100$ atoms [FIG. 4(c)]. In the second, third, and fourth layers, the largest island sizes are 305, 69, and 12 atoms, respectively. Overall, films grown with $\mathrm{N} / \mathrm{Ti}=2$ exhibit the smoothest surfaces with the largest number of atoms in the first layer and the least number of atoms in the third and fourth layers.

The choice of N/Ti ratios during film growth has a dramatic effect not only on nanostructural and surface morphological evolution, but also on island shapes and edge orientations. The 100 edges of epitaxial TiN islands are non-polar, while the 110 edges are polar. Thus, changes in N/Ti flux ratios are expected to alter the dominant edge orientation. Figure 5 compares relative edge orientations of first-layer islands as a function of Ti coverage $\theta_{1, \mathrm{Ti}}$ for the three $\mathrm{N} / \mathrm{Ti}$ ratios. The solid blue lines indicate the total length $\mathrm{L}_{100}$, in atoms, of 100 edges and the dashed red lines the total length $\mathrm{L}_{110}$ of 110 edges. We define the fractional length $\zeta$ of 100 and 110 edges as $\zeta_{100}=$ $\mathrm{L}_{100} /\left(\mathrm{L}_{100}+\mathrm{L}_{110}\right)$ and $\zeta_{110}=\mathrm{L}_{110} /\left(\mathrm{L}_{100}+\mathrm{L}_{110}\right)$. 

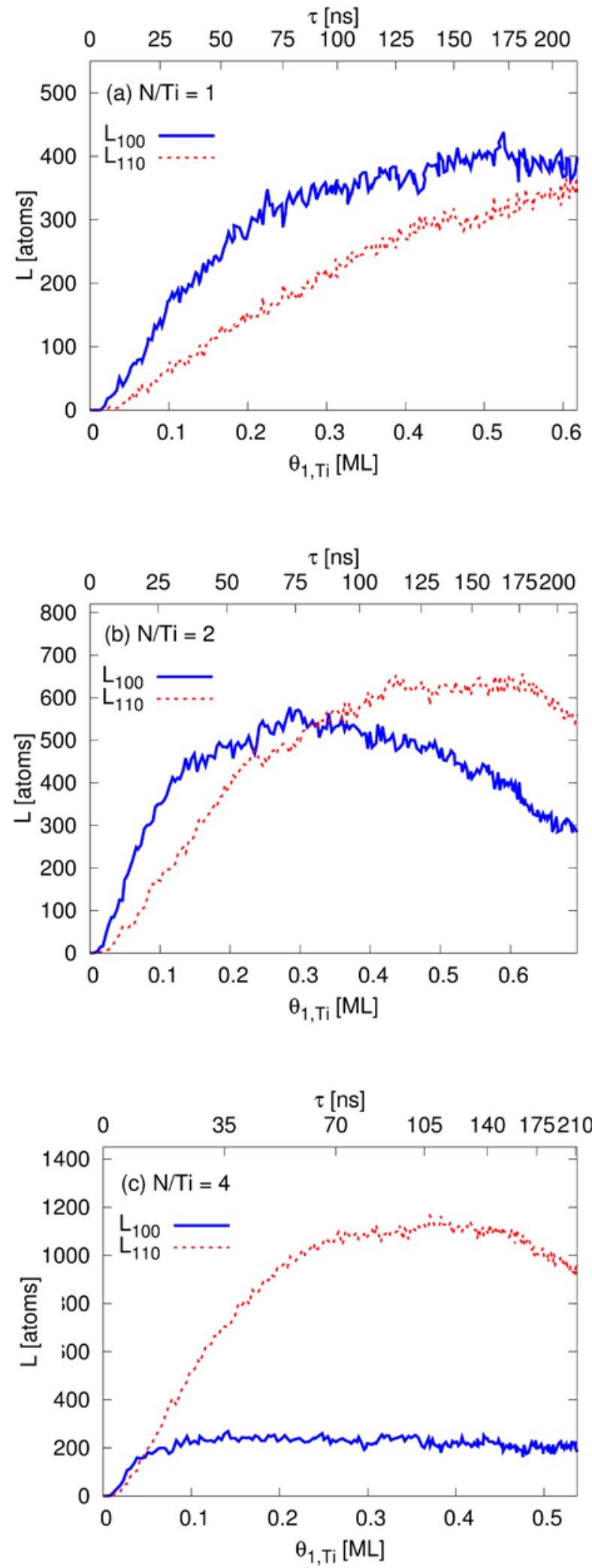
FIG. 5. Total length L, in atoms, of 100 and 110 island edges as a function of first-layer Ti coverage $\theta_{1, \mathrm{Ti}}$ during TiN/TiN(001) film growth at $1200 \mathrm{~K}$ with N/Ti ratios of (a) one, (b) two, and (c) four. The substrate size is $2121 \times 2121 \AA^{2}$ (100x100 atoms). The solid blue line corresponds to $\mathrm{L}_{100}$ and the dashed red line to $\mathrm{L}_{110}$.

FIG. 5(a), corresponding to the first layer in N/Ti $=1$ films, shows that, while both 100- and 110-oriented island edges are formed, there is an initial preference toward 100. However, by the end of film growth, $\theta_{1, \mathrm{Ti}}=0.61 \mathrm{ML}\left(\theta_{\mathrm{tot}, \mathrm{Ti}}=0.81 \mathrm{ML}\right), \mathrm{L}_{110}$ has become nearly equal to $\mathrm{L}_{100}, \zeta_{110}=0.47$ and $\zeta_{100}=0.53$. For film growth with N/Ti $=2$, 100-oriented edges are also preferred initially, but $\mathrm{L}_{110}$ becomes equal to $\mathrm{L}_{100}$ at $\theta_{1, \mathrm{Ti}} \simeq$ 0.3 ML. With further deposition, N-terminated 110-oriented edges dominate (i.e, $\zeta_{100}$ decreases) in order to accommodate excess nitrogen incorporation [FIG. 5(b)]. At the end of $\mathrm{N} / \mathrm{Ti}=2$ film growth, $\theta_{1, \mathrm{Ti}}=0.69 \mathrm{ML}, 110$ edges are favored with $\zeta_{110}=0.66$. During growth of the $\mathrm{N} / \mathrm{Ti}=4$ layer, 110 edges begin to dominate very early, at $\theta_{1, \mathrm{Ti}} \simeq 0.05 \mathrm{ML}$, as shown in FIG. 5(c). $\zeta_{110}$ continues to increase with further deposition and reaches 0.82 at the end of film growth at which $\theta_{1, \mathrm{Ti}}=0.54$ and $\theta_{\mathrm{tot}, \mathrm{Ti}}=0.82 \mathrm{ML}$.

From Figure 5, it is clear that for films grown with N/Ti $=2$ and, especially, N/Ti $=4$, the islands are primarily bounded by polar edges and, hence, terminated with $\mathrm{N}$ atoms. In order to provide better estimates of bulk-layer compositions, we count only atoms in first layers which have four in-plane nearest-neighbors. Bulk compositions for $\mathrm{N} / \mathrm{Ti}=1,2$, and 4 films are $\mathrm{TiN}_{0.78}, \mathrm{TiN}_{0.98}$, and $\mathrm{TiN}_{1.09}$, respectively. Thus, films grown with N/Ti $=2$ and 4 are nearly stoichiometric, as expected, with N-saturated 110 island edges.

We also track the number of substrate surface vacancies vs. first-layer $\mathrm{Ti}$ coverage $\theta_{1, \mathrm{Ti}}$. For deposition with $\mathrm{N} / \mathrm{Ti}=1$, it is primarily $\mathrm{N}$ vacancies that are formed, 
with very few Ti vacancies. After $\tau=212.5 \mathrm{~ns}$ of deposition $\left(\theta_{1, \mathrm{Ti}}=0.61, \theta_{\mathrm{tot}, \mathrm{Ti}}=0.81\right.$ $\mathrm{ML}$ ), there are $61 \mathrm{~N}$ vacancies $\mathrm{V}_{\mathrm{N}}$ in the $100 \times 100$ atom substrate surface, corresponding to a surface vacancy number density on the anion sublattice of $\mathrm{D}_{\mathrm{V}, \mathrm{N}}=1.2 \%$. In contrast, there are only $3 \mathrm{Ti}$ vacancies $\mathrm{V}_{\mathrm{Ti}}$ on the cation sublattice $\left(\mathrm{D}_{\mathrm{V}, \mathrm{Ti}}=0.06 \%\right)$. For film growth with $\mathrm{N} / \mathrm{Ti}=2\left(\theta_{1, \mathrm{Ti}}=0.69 \mathrm{ML}\right)$, there are substantially fewer surface vacancies created, with a much lower $\mathrm{V}_{\mathrm{N}} / \mathrm{V}_{\mathrm{Ti}}$ ratio: $\mathrm{V}_{\mathrm{N}}=13\left(\mathrm{D}_{\mathrm{V}, \mathrm{N}}=0.26 \%\right)$ and $\mathrm{V}_{\mathrm{Ti}}=8\left(\mathrm{D}_{\mathrm{V}, \mathrm{Ti}}=\right.$ $0.16 \%)$. With $\mathrm{N} / \mathrm{Ti}=4, \mathrm{~V}_{\mathrm{Ti}}$ dominate; Ti vacancies begin forming early in the deposition process and continue to be created until the $\mathrm{V}_{\mathrm{Ti}}$ concentration saturates at $\sim 70 \mathrm{Ti}$ vacancies $\left(\mathrm{D}_{\mathrm{V}, \mathrm{Ti}} \simeq 1.4 \%\right)$ at $\theta_{1, \mathrm{Ti}}=0.41 \mathrm{ML}(\tau=120 \mathrm{~ns})$. In contrast, the number of $\mathrm{N}$ vacancies remains at a low level throughout film growth, peaking at $\mathrm{V}_{\mathrm{N}}=7\left(\mathrm{D}_{\mathrm{V}, \mathrm{N}}=\right.$ $0.14 \%)$ with $\theta_{1, \mathrm{Ti}}=0.09 \mathrm{ML}$. The observed transition from primarily $\mathrm{N}$-vacancy to primarily Ti-vacancy formation is controlled, as expected, by the incident N/Ti ratio. With increasing $\mathrm{N} / \mathrm{Ti}$, the likelihood of $\mathrm{Ti}$ atoms migrating from the substrate into the first deposited layer increases. In parallel, $\mathrm{N}$ atoms lost due to the formation and desorption of $\mathrm{N}_{2}$ molecules are more easily replaced by excess $\mathrm{N}$ in the deposition flux, resulting in fewer net nitrogen vacancies.

To verify the stability of the as-deposited island sizes, we allow the films to relax for 5000 ps at $1200 \mathrm{~K}$ without depositing additional atoms. This annealing/relaxation process yields only minor effects, primarily slight size reductions in the larger upperlayer islands due to dissociation. In addition, there is a general decrease in the density of the smallest islands in all layers giving rise to surface smoothening. For $\mathrm{N} / \mathrm{Ti}=1$ films, the total number of atoms remains constant during relaxation. However, for $\mathrm{N} / \mathrm{Ti}=2$ and $\mathrm{N} / \mathrm{Ti}=4$, the total number of $\mathrm{N}$ atoms decreases by 10 and 77, respectively, due to 
$\mathrm{N}_{\mathrm{ad}} / \mathrm{N}_{\text {surf }}$ desorption. Regarding edge orientations, $\zeta_{110}$ slightly increases upon relaxation, from $0.47,0.66$ and 0.82 for $\mathrm{N} / \mathrm{Ti}=1,2$, and 4 , to $0.50,0.67$, and 0.84 .

When the $\mathrm{N}$ supply during $\operatorname{TiN} / \operatorname{TiN}(001)$ growth is stochastically deficient locally, this leads to excess metal atoms occupying non-epitaxial sites and the formation of small 111-oriented islands. These results are in agreement with previous crosssectional transmission electron microscopy observations of local epitaxial breakdown during reactive sputter deposition of $\mathrm{TaN} / \mathrm{MgO}(001)$ films as the nitrogen/metal ratio was decreased below a critical value. ${ }^{42}$ The authors had speculated that nucleation of 111oriented $\operatorname{TaN}_{\mathrm{x}}(\mathrm{x}<1)$ columns within epitaxial $\mathrm{TaN}(001)$ layers was due to "surface regions stochastically encountering an insufficient $\mathrm{N}$ supply to sustain epitaxial growth.” Furthermore, the authors ${ }^{42}$ conjectured that the 111 columns were initiated by Ta adatoms forming close-packed N-deficient islands. The present results validate the general conclusions $^{42}$ and reveal the atomistic mechanism of 111-column nucleation via the formation and growth of the ladder-like structure, shown in Figure 3(c), with Ti atoms residing in fourfold-hollow positions.

As the $\mathrm{N} / \mathrm{Ti}$ ratio is increased from 2 to 4 , we observe changes in film morphology which can also be compared to prior experimental results. It has been demonstrated, ${ }^{21}$ using scanning tunneling microscopy, that nucleation kinetics of homoepitaxial TiN(001) layers grown by ultra-high vacuum reactive magnetron sputtering in mixed $\mathrm{N}_{2} / \mathrm{Ar}$ discharges are strongly affected by the $\mathrm{N}_{2}$ partial pressure during deposition. Increasing the $\mathrm{N}_{2}$ fraction in the gas mixture from 0.10 to 1.00 resulted in a factor of two decrease in the critical island size $R_{c}$ required to nucleate a new layer island. Thus, film roughness increased faster with film growth at higher 
nitrogen fluxes. This is in agreement with the results of this study showing that films grown with $\mathrm{N} / \mathrm{Ti}=4$ are rougher than $\mathrm{N} / \mathrm{Ti}=2$ films with more atoms residing in islands in the third and fourth layers.

\section{IV.SUMMARY AND CONCLUSIONS}

We have performed large scale-simulations of epitaxial TiN/TiN(001) thin film growth at $T_{\mathrm{s}}=1200 \mathrm{~K}$ with $\mathrm{N} / \mathrm{Ti}$ flux ratios of 1,2 and 4 . The results provide detailed insights into the mechanisms by which changing the incident N/Ti flux ratio strongly affects not only film stoichiometry, but also island nanostructure, surface morphology, and island-edge termination. At low N/Ti ratios, films are globally understoichiometric with surfaces which contain small metal-rich 111-oriented regions. In this regime, multilayer growth is prevalent and both 100- and 110-bounded epitaxial islands are formed, with the former being the majority. As N/Ti is increased, 110 islands with Nterminated edges become increasingly dominant. Deposition with $\mathrm{N} / \mathrm{Ti}=2$ and 4 results in films whose growth mode is closer to ideal layer-by-layer; the films are nearly stoichiometric with excess $\mathrm{N}$ accommodated at $\mathrm{N}$-terminated polar 110 island edges. Our results indicate that an insufficient N/Ti incident flux ratio leads to surface roughening via nucleation of 111 islands, whereas high N/Ti ratios result in surface roughening due to more rapid upper-layer nucleation and mound formation. The growth mode of N/Ti $=2$ films, which have smoother surfaces, is closer to layer-by-layer.

\section{ACKNOWLEDGMENTS}

Calculations were performed using resources provided by the Swedish National Infrastructure for Computing (SNIC), on the Neolith, Kappa, and Triolith Clusters located at the National Supercomputer Centre (NSC) at Linköping University. We also appreciate the financial support from the Swedish Research Council (VR) Linköping 
Linnaeus Initiative LiLi-NFM (grant 2008-6572) and Project Grants 2009-00971, 2013-

4018, and 2014-5790; the Swedish Government Strategic Research Area Grant in Materials Science on Advanced Functional Materials; and the Knut and Alice Wallenberg Foundation (Isotope Project).

${ }^{1}$ H. Ljungcrantz, M. Odén, L. Hultman, J. E. Greene, and J.-E. Sundgren, J. Appl. Phys. 80, 6725 (1996).

${ }^{2}$ J.-E. Sundgren, Thin Solid Films 128, 21 (1985).

${ }^{3}$ J. E. Greene, J.-E. Sundgren, L. Hultman, I. Petrov, and D. B. Bergstrom, Appl. Phys. Lett. 67, 2928 (1995).

${ }^{4}$ T. Reeswinkel, D. G. Sangiovanni, V. Chirita, L. Hultman, and J. M. Schneider, Surf. Coat. Technol. 205, 4821 (2011).

${ }^{5}$ C.-S. Shin, D. Gall, N. Hellgren, J. Patscheider, I. Petrov, and J. E. Greene, J. Appl. Phys. 93, 6025 (2003).

${ }^{6}$ P. Hedenqvist, M. Bromark, M. Olsson, S. Hogmark, and E. Bergmann, Surf. Coat. Technol. 63, 115 (1994).

${ }^{7}$ T. Polcar, T. Kubart, R. Novák, L. Kopecký, and P. Široký, Surf. Coat. Technol. 193, 192 (2005).

${ }^{8}$ A. S. Ingason, F. Magnus, J. S. Agustsson, S. Olafsson, and J. T. Gudmundsson, Thin Solid Films 517, 6731 (2009).

${ }^{9}$ D. McIntyre, J. E. Greene, G. Håkansson, J.-E. Sundgren, and W.-D. Münz, J. Appl. Phys. $671542(1990)$.

${ }^{10}$ L. A. Donohue, I. J. Smith, W.-D. Münz, I. Petrov, and J. E. Greene, Surf. Coat. Technol. 94-95, 226 (1997).

${ }^{11}$ A. B. Mei, A. Rockett, L. Hultman, I. Petrov, and J. E. Greene, J. Appl. Phys. 114, 193708 (2013).

${ }^{12}$ H.-S. Seo, T.-Y. Lee, J. G. Wen, I. Petrov, J. E. Greene, and D. Gall, J. Appl. Phys. 96, 878 (2004). 
${ }^{13}$ C.-S. Shin, S. Rudenja, D. Gall, N. Hellgren, T.-Y. Lee, I. Petrov, and J. E. Greene, J. Appl. Phys. 95, 356 (2004).

${ }^{14}$ D. Gall, I. Petrov, N. Hellgren, L. Hultman, J. E. Sundgren, and J. E. Greene, J. Appl. Phys. 84, 6034 (1998).

${ }^{15}$ D. Gall, I. Petrov, and J. E. Greene, J. Appl. Phys. 89, 401 (2001).

${ }^{16}$ H.-S. Seo, T.-Y. Lee, I. Petrov, J. E. Greene, and D. Gall, J. Appl. Phys. 97, 083521 (2005).

${ }^{17}$ C.-S. Shin, D. Gall, Y.-W. Kim, P. Desjardins, I. Petrov, J. E. Greene, M. Odén, and L. Hultman, J. Appl. Phys. 90, 2879 (2001).

${ }^{18}$ J.E. Sundgren, B.O. Johansson, A. Rockett, S.A. Barnett, and J.E. Greene, "TiN: A Review of the Present Understanding of the Atomic and Electronic Structure and Recent Results on the Growth and Physical Properties of Epitaxial TiNx $(0.6<\mathrm{x}<.12)$ Layers," in Physics and Chemistry of Protective Coatings, Ed. by J.E. Greene, W.D. Sproul, and J.A. Thornton, American Institute of Physics Series 149, New York, (1986), p. 95.

${ }^{19}$ H. A. Wriedt and J. L. Murray, Bull. Alloy Phase Diagrams 8, 378 (1987)

${ }^{20}$ M. A. Wall, D. G. Cahill, I. Petrov, D. Gall, and J. E. Greene, Phys. Rev. B 70, 035413 (2004).

${ }^{21}$ M. A. Wall, D. G. Cahill, I. Petrov, D. Gall, and J. E. Greene, Surf. Sci. 581, L122 (2005).

${ }^{22}$ S. Kodambaka, V. Petrova, A. Vailionis, P. Desjardins, D. G. Cahill, I. Petrov, and J. E. Greene, Thin Solid Films 392, 164 (2001).

${ }^{23}$ S. Kodambaka, V. Petrova, A. Vailionis, I. Petrov, and J. E. Greene, Surf. Sci. 526, 85 (2003).

${ }^{24}$ F. H. Baumann, D. l. Chopp, T. D. de la Rubia, G. E. Gilmer, J. E. Greene, H. Huang, S. Kodambaka, P. O’Sullivan, and I. Petrov, MRS Bull. 26, 182 (2001).

${ }^{25}$ S. Kodambaka, S. V. Khare, V. Petrova, A. Vailionis, I. Petrov, and J. E. Greene, Surf. Sci. 513, 468 (2002).

${ }^{26}$ U. Helmersson, J.-E. Sundgren, and J. E. Greene, J. Vac. Sci. Technol. A 4, 500 (1986). 
${ }^{27}$ B. W. Karr, I. Petrov, P. Desjardins, D. G. Cahill, and J. E. Greene, Surf. Coat. Technol. 94-95, 403 (1997).

${ }^{28}$ S. Kodambaka, V. Petrova, A. Vailionis, P. Desjardins, D. G. Cahill, I. Petrov, and J. E. Greene, Surf. Rev. Lett. 07, 589 (2000).

${ }^{29}$ F. Watanabe, S. Kodambaka, W. Swiech, J. E. Greene, and D. G. Cahill, Surf. Sci. 572, 425 (2004).

${ }^{30}$ S. Kodambaka, N. Israeli, J. Bareño, W. Święch, K. Ohmori, I. Petrov, and J. E. Greene, Surf. Sci. 560, 53 (2004).

${ }^{31}$ D. G. Sangiovanni, D. Edström, L. Hultman, V. Chirita, I. Petrov, and J. E. Greene, Phys. Rev. B 86, 155443 (2012).

${ }^{32}$ D. Edström, D. G. Sangiovanni, L. Hultman, V. Chirita, I. Petrov, and J. E. Greene, Thin Solid Films 558, 37 (2014).

${ }^{33}$ D. Edström, D. G. Sangiovanni, L. Hultman, I. Petrov, J. E. Greene, and V. Chirita, Thin Solid Films 589, 133 (2015).

${ }^{34}$ L. Hultman, S. A. Barnett, J.-E. Sundgren, and J. E. Greene, J. Cryst. Growth 92, 639 (1988).

${ }^{35}$ B.-J. Lee and M. I. Baskes, Phys. Rev. B 62, 8564 (2000).

${ }^{36}$ S. Plimpton, J. Comput. Phys. 117, 1 (1995).

${ }^{37}$ D. G. Sangiovanni, D. Edström, L. Hultman, I. Petrov, J. E. Greene, and V. Chirita, Surf. Sci. 627, 34 (2014).

${ }^{38}$ D. G. Sangiovanni, D. Edström, L. Hultman, I. Petrov, J. E. Greene, and V. Chirita, Surf. Sci. 624, 25 (2014).

${ }^{39}$ I. Petrov, A. Myers, J. E. Greene, and J. R. Abelson, J. Vac. Sci. Technol. A 12

${ }^{40}$ W. Humphrey, A. Dalke, and K. Schulten, J. Mol. Graph. 14, 33 (1996).

${ }^{41}$ Z. Xu, Q. Zeng, L. Yuan, Y. Qin, M. Chen, and D. Shan, Appl. Surf. Sci. 360, 946 (2016).

${ }^{42}$ C.-S. Shin, Y.-W. Kim, N. Hellgren, D. Gall, I. Petrov, and J. E. Greene, J. Vac. Sci. Technol. Vac. Surf. Films 20, 2007 (2002). 
FIG. 1. (Color online) Positions, viewed along 001, of all deposited atoms (upper panels) during TiN/TiN(001) film growth at $1200 \mathrm{~K}$ following total incident Ti exposures of 4250 atoms with N/Ti ratios of (a) one, (b) two, and (c) four. The substrate size is 2121x2121 $\AA^{2}$ (100x100 atoms). Ti and $N$ atoms are color coded by layer number as shown in the legend. The layer numbers are defined by intervals of $2.1 \AA$ in the growth direction. The lower panels in (a), (b), and (c) are plots of the total numbers of captured Ti and $N$ atoms ( $n_{T i}$ and $n_{N}$ ) as a function of Ti coverage in the first layer $\theta_{1, T i}$ [ML]. $\tau$ is the deposition time.

FIG. 2. (Color online) Positions, viewed along 001, of all deposited atoms in the first layer during TiN/TiN(001) film growth at $1200 \mathrm{~K}$ following total incident Ti exposures of 4250 atoms with N/Ti ratios of (a) one, (b) two, and (c) four. The substrate size is 2121x2121 $\AA^{2}$ (100x100 atoms). Ti and N atoms are color coded as shown in Figure 1.

FIG. 3. (Color online) Common island structures during TiN/TiN(001) film growth at $1200 \mathrm{~K}$ with $\mathrm{N} / \mathrm{Ti}=1$. All panels are oriented $<100>$ in the horizontal direction and $<010>$ vertically. (a) $\mathrm{Ti}_{2} \mathrm{~N}_{2}$ square island with 100 edges and all atoms in epitaxial atop positions. (b) Triangular island with three Ti atoms in fourfold-hollow sites and a $\mathrm{N}$ atom in an epitaxial atop position. (c) $\mathrm{Ti}_{4} \mathrm{~N}$ pentamer structure with all atoms in fourfoldhollow sites. (d) Ladder-like structure consisting of pentamer chains in which both Ti and $\mathrm{N}$ atoms are in fourfold-hollow sites. (e) A 111-oriented TiN/TiN(001) island formed from a ladder structure island by growth in 110 directions. The hexagonal unit cell is highlighted with green dash/dot lines.

FIG. 4. (Color online) TiN/TiN(001) island size distributions as a function of layer number following total incident Ti exposures of 4250 atoms with N/Ti ratios of (a) one, (b) two, and (c) four during film growth at $1200 \mathrm{~K}$. The substrate size is $2121 \times 2121 \AA^{2}$ (100x100 atoms). Island size distributions are plotted as the logarithm of the total number of atoms $\mathrm{n}_{\text {tot }}$ vs. island size in units of the total number of atoms per island.

FIG. 5. (Color online) Total length $\mathrm{L}$, in atoms, of 100 and 110 island edges as a function of first-layer Ti coverage $\theta_{1, \mathrm{Ti}}$ during TiN/TiN(001) film growth at $1200 \mathrm{~K}$ with N/Ti 
ratios of (a) one, (b) two, and (c) four. The substrate size is $2121 \times 2121 \AA^{2}(100 \times 100$ atoms). The solid blue line corresponds to $\mathrm{L}_{100}$ and the dashed red line to $\mathrm{L}_{110}$. 